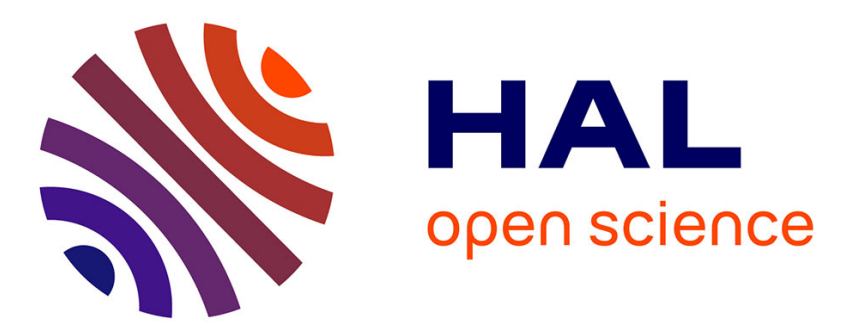

\title{
High temperature tribological behaviour of metal matrix composites produced by SPS
}

Solisabel Orozco Gomez, Karl Delbé, Alberto Benitez, Jean Yves Paris, Jean

Denape

\section{- To cite this version:}

Solisabel Orozco Gomez, Karl Delbé, Alberto Benitez, Jean Yves Paris, Jean Denape. High temperature tribological behaviour of metal matrix composites produced by SPS. Key Engineering Materials, 2011, vol. 482, pp. 89-100. 10.4028/www.scientific.net/KEM.482.89 . hal-00881328

\section{HAL Id: hal-00881328 \\ https://hal.science/hal-00881328}

Submitted on 8 Nov 2013

HAL is a multi-disciplinary open access archive for the deposit and dissemination of scientific research documents, whether they are published or not. The documents may come from teaching and research institutions in France or abroad, or from public or private research centers.
L'archive ouverte pluridisciplinaire HAL, est destinée au dépôt et à la diffusion de documents scientifiques de niveau recherche, publiés ou non, émanant des établissements d'enseignement et de recherche français ou étrangers, des laboratoires publics ou privés. 


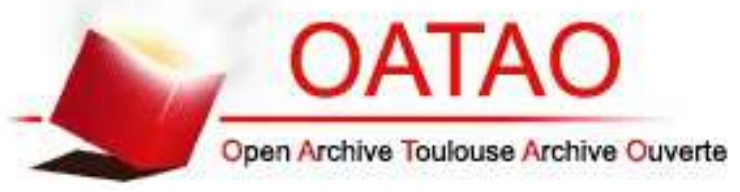

\section{Open Archive Toulouse Archive Ouverte (OATAO)}

OATAO is an open access repository that collects the work of Toulouse researchers and makes it freely available over the web where possible.

This is an author-deposited version published in: http://oatao.univ-toulouse.fr/ Eprints ID: 9776

To link to this article: DOI:10.4028/www.scientific.net/KEM.482.89 http://dx.doi.org/10.4028/www.scientific.net/KEM.482.89

\section{To cite this version:}

Orozco Gomez, Solisabel and Delbe, Karl and Benitez, Alberto and Paris, Jean Yves and Denape, Jean High Temperature Tribological Behaviour of Metal Matrix Composites Produced by SPS. (2011) Key Engineering Materials, vol. 482 . pp. 89100. ISSN 1662-9795

Any correspondence concerning this service should be sent to the repository administrator: staff-oatao@ listes-diff.inp-toulouse.fr 


\title{
High temperature tribological behaviour of metal matrix composites produced by SPS
}

\author{
OROZCO GOMEZ Solisabel ${ }^{1}$, DELBÉ Karl ${ }^{1, a}$, BENITEZ Alberto ${ }^{1}$, \\ PARIS Jean-Yves ${ }^{1}$, DENAPE Jean ${ }^{1}$ \\ ${ }^{1}$ LGP, ENIT-INPT, Université de Toulouse, 47, avenue d'Azereix, BP 1629 - 65016 -TARBES \\ CEDEX \\ a Karl.Delbe@enit.fr
}

Key words: Tribology, wear, metal matrix composites, solid lubricants.

\begin{abstract}
Materials used as friction components in transportation field are subjected to extreme working conditions: they rapidly reach their structural limits and critical parts require to be regularly replaced. Alternative solutions withstanding higher operating conditions imply to find innovative materials. Steel matrix composites including various solid lubricants, $\mathrm{WS}_{2}$ and $\mathrm{h}-\mathrm{BN}$, able to support high temperatures were developed using a Spark Plasma Sintering technique, which makes possible the formation of new microstructures out of reach by conventional means. Sliding tests were conducted using a pin-on-disc tribometer in air at $450^{\circ} \mathrm{C}$, with a normal load of $15 \mathrm{~N}$ and various velocities ranged from 0.1 to $1.5 \mathrm{~m} / \mathrm{s}$. Influence of solid lubricant content and sensitivity to test parameters were studied in terms of friction and wear responses of the contacting materials. Test results reveal an improvement of friction properties for composites containing highest $\mathrm{WS}_{2}$ contents. A reduction of wear is quantified for all composites, and the best behaviour is observed for those that contain $\mathrm{WS}_{2}$. In agreement with the third body approach, interpretations are proposed to describe the interphase dynamics within the contact.
\end{abstract}

\section{Introduction}

In current industry, mechanical devices assume to support severe environmental conditions: high temperature and stresses under reactive and corrosive conditions. Economic pressures and new environmental standards require manufacturers to find innovative solutions for the replacement of out-of-date parts. Insertion of a solid lubricant in a metallic matrix in order to reduce friction has already been considered widely by using conventional sintering method $[1,2,3,4]$.

Metal Matrix Composites (MMC) manufactured by Spark Plasma Sintering (SPS) provide original solutions for the synthesis of new materials inaccessible by conventional techniques. Thus, MMC containing different contents of solid lubricants such as hexagonal boron nitride (h-BN) or tungsten disulphide $\left(\mathrm{WS}_{2}\right)$ were worked out $[1,5]$. The presence of solid lubricant in the composite bulk and, in particular, on it surface, expects the formation of a tribofilm, so called third body, which will allow the velocities accommodation between surfaces in contact $[6,7]$.

The present study concerns four MMC containing solid lubricants trapped in a steel matrix. Mechanisms responsible for the tribological behaviour are identified and discussed. This approach is completed by surface topography measurements, observations of the third body morphology and chemical analyses of detached particles that compose the third body.

\section{Materials studied}

Metal Matrix Composites were synthesized under uniaxial pressure using a powder consolidation technology called Spark Plasma Sintering $[8,9]$. The temperature of densification proceeds from current pulses of very high intensity, which directly pass through graphite dies and disperse spark plasma energy between particles of powder. This operation takes only a few minutes. The apparatus performed for this study is a Sumitomo Model 2080 located at the Plateforme Nationale de Frittage Flash ( $\left.\mathrm{PNF}^{2}-\mathrm{CNRS}\right)$ in Toulouse, France [10]. This is one of the most powerful machines in Europe in terms of current pulses (1-8000 A under 0-10 V) and sample size (up to $50 \mathrm{~mm}$ in diameter). Applied uniaxial pressure and sintering temperature can reach respectively $200 \mathrm{MPa}$ and $2000^{\circ} \mathrm{C}$. 
The matrix of these composites is made of steel containing $18 \%$ in chromium and $10 \%$ in nickel (by weight). This stainless steel, without solid lubricant, so called 18-10 steel, was chosen as a reference for the study. Different contents of hexagonal boron nitride (h-BN) or tungsten disulphide (WS2) solid lubricants are introduced into the steel matrix.

Table 1 presents the sintering conditions of the five studied materials and their designation used in this paper. SPS conditions are optimized to obtain the best compaction of the material. In this way, the SPS conditions for A10BN are different in comparison to the others.

Table 1: Compositions and sintering conditions of the different studied MMC.

\begin{tabular}{lll}
\hline Materials & SPS Conditions & Nomenclature \\
\hline \hline Stainless Steel $(18 \%$ Cr- $10 \% \mathrm{Ni})$ & $900^{\circ} \mathrm{C}, 2 \mathrm{~min}, 80 \mathrm{MPa}$ & $18-10$ Steel \\
18-10 Steel $-10 \%$ (vol.) BN & $800^{\circ} \mathrm{C}, 4 \mathrm{~min}, 75 \mathrm{MPa}$ & $\mathrm{A} 10 \mathrm{BN}$ \\
18-10 Steel $-20 \%$ (vol.) $\mathrm{BN}$ & $900^{\circ} \mathrm{C}, 2 \mathrm{~min}, 75 \mathrm{MPa}$ & $\mathrm{A} 20 \mathrm{BN}$ \\
18-10 Steel $-8 \%$ (vol.) $\mathrm{WS}_{2}$ & $900^{\circ} \mathrm{C}, 2 \mathrm{~min}, 75 \mathrm{MPa}$ & $\mathrm{A} 8 \mathrm{WS}_{2}$ \\
18-10 Steel $-12 \%$ (vol.) $\mathrm{WS}_{2}$ & $900^{\circ} \mathrm{C}, 2 \mathrm{~min}, 75 \mathrm{MPa}$ & $\mathrm{A} 12 \mathrm{WS}_{2}$ \\
\hline
\end{tabular}

\section{Experimental details}

Tribological tests were performed using a Pin-on-disc configuration [11, 12]. All pins are stainless steel AISI 431, and have a cylindrical shape of $6 \mathrm{~mm}$ diameter. Vickers hardness of the pins is 247 HV30. Discs and pins were polished and cleaned in ultrasonic baths of ethanol prior testing. Tests are performed at a constant load of $15 \mathrm{~N}$ while the velocity increases by steps from $0.25 \mathrm{~m} / \mathrm{s}$ to $1.5 \mathrm{~m} / \mathrm{s}$. Each steps has duration of $300 \mathrm{~s}$. The normal load applied on the pin and tangential force are continuously measured throughout a computerized data acquisition system. The friction coefficient is calculated according to the Amontons' law [13], i.e. the ratio of tangential force and normal load, while the wear rate is quantified using the Archard model [14].

Samples are heated up to $450^{\circ} \mathrm{C}$ by a radiative furnace surrounding the contact and thermocouples control the temperature in the vicinity of the contact. All tests are performed in air at atmospheric pressure.

Table 2 summarizes the operating conditions.

Table 2: Operating conditions of the tribometer.

\begin{tabular}{ll}
\hline Configuration & Plate on plate \\
Type of movement & Continues rotation \\
Pin diameter & $6 \mathrm{~mm}$ \\
Contact area & $113 \mathrm{~mm}^{2}$ \\
Temperature & $450^{\circ} \mathrm{C}$ \\
Environment & Air - atmospheric pressure \\
\hline
\end{tabular}

\section{Study of friction-reducing properties}

Characteristic friction coefficient curves are represented as a function of time and the velocity for each composite in Fig. 1 to Fig. 3. 


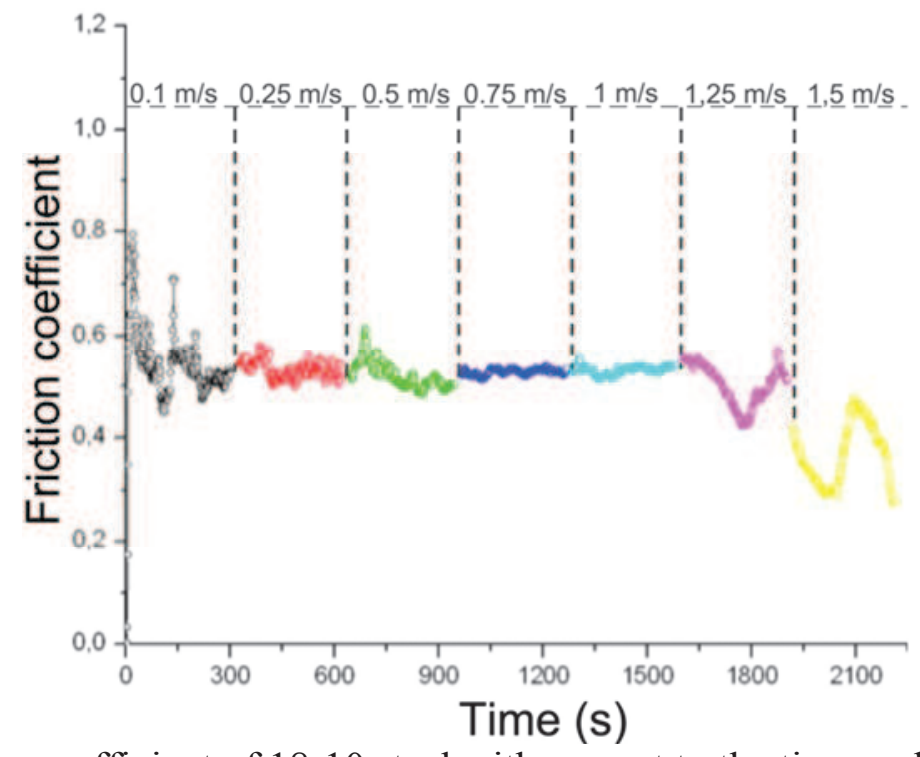

Figure 1: Friction coefficient of 18-10 steel with respect to the time and sliding velocity.

In the case of 18-10 steel, the friction coefficient start at 0.8 , decrease rapidly and remains constant at 0.52 from $0.1 \mathrm{~m} / \mathrm{s}$ to $1.25 \mathrm{~m} / \mathrm{s}$. Up to $1.25 \mathrm{~m} / \mathrm{s}$, it becomes unstable and falls to minimum values, around 0.3 .

Tribological tests carried out with composites containing hexagonal boron nitride i.e. A10BN (Fig.2 a) and A20BN, (Fig.2 b), register average friction coefficients higher than 0.7.

With A10BN discs, the friction coefficient presents an unstable behaviour, which values oscillate between 0.8 and 1. High friction force and important adhesion phenomena between the pin and the disc are responsible to these results. A catastrophic degradation of the samples imposed a premature interruption of the test.

In the case of A20BN, the friction coefficient is smaller at the beginning of the test and increases during the first two velocity steps. The friction coefficient is maximized at the second and the third velocity steps to a value near of 0.9 . The frictional force oscillates during the third step and the friction coefficient associated is measured between 0.7 and 0.8 .

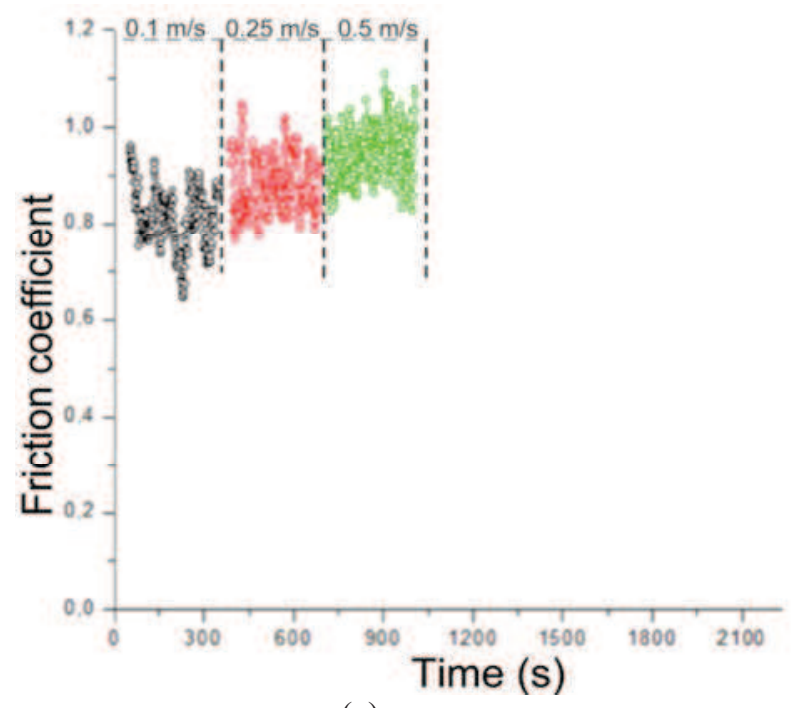

(a)

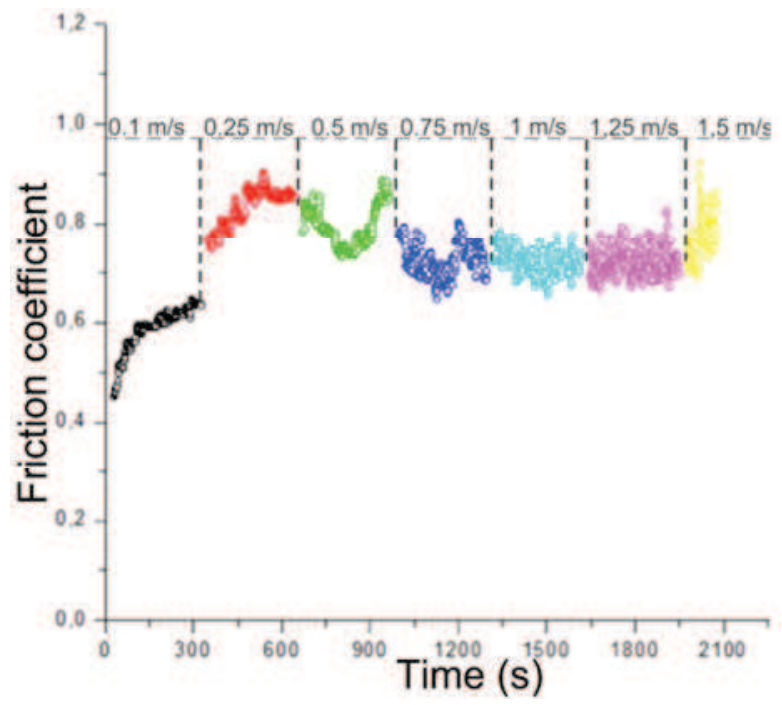

(b)

Figure 2: Friction coefficient of A10BN (a) and A20BN (b) with respect to the time and sliding velocity. 
During the next step, at $0.75 \mathrm{~m} / \mathrm{s}$, the fiction coefficient presents a mean value around 0.7 . Until the end of the tribological test, friction coefficient presents a high instability. A catastrophic degradation of the samples is also observed and imposed an interruption of the test during the last step.

In the case of $\mathrm{A}_{8 \mathrm{WS}}$ composite, the friction coefficients are relatively stable, with values varying around 0.5 . During some steps, at $0.75,1.25$ and $1.5 \mathrm{~m} / \mathrm{s}$, the friction coefficient decreases quickly to values inferior to 0.5 during a very short range of time.

In the case of $\mathrm{A}_{12} \mathrm{WS}_{2}$, the friction coefficient is starting around 0.3 and increase regularly with the increase of the velocity. However, when the sliding velocities are greater or equal than $1.25 \mathrm{~m} / \mathrm{s}$, this composite shows the lowest values of friction coefficient, which can decrease down to 0.3 .

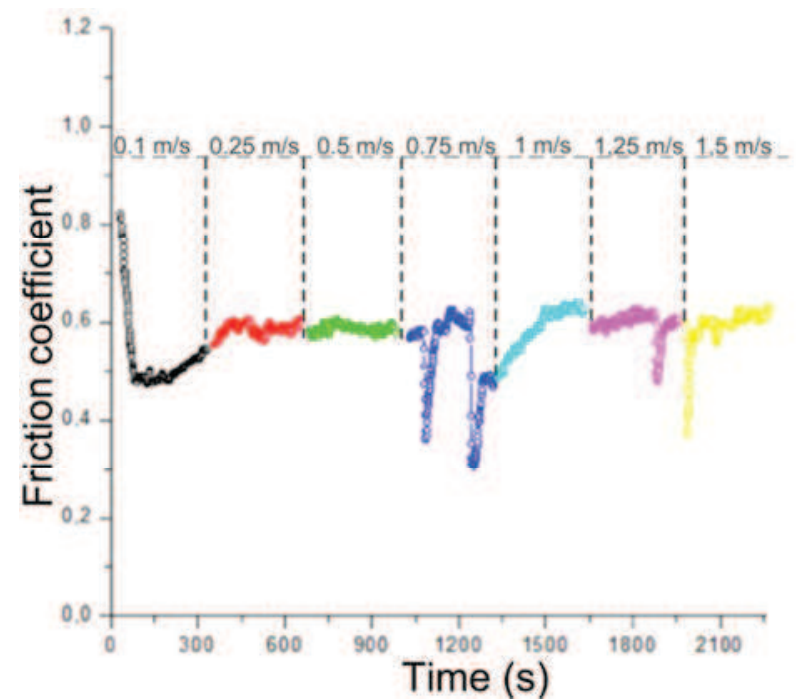

(a)

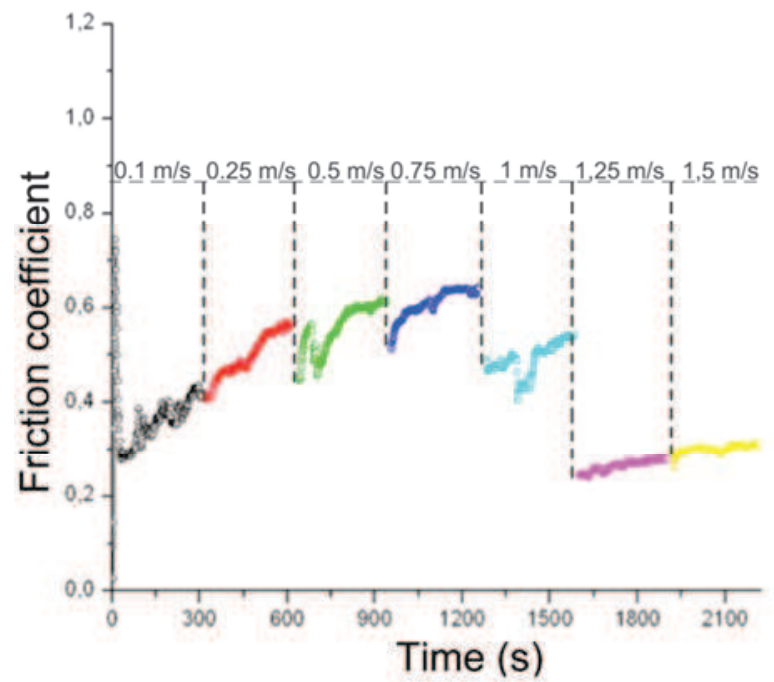

(b)

Figure 3: Friction coefficient of $\mathrm{A}^{8} \mathrm{WS}_{2}$ (a) and $\mathrm{A} 12 \mathrm{WS}_{2}$ (b) with respect to the time and sliding velocity.

\section{Optical and topographical analysis}

Optical microscope observations are realized before tribological tests (Fig. 4). On the A10BN composite, white particles with fine granularity and well distributed are associated to the h-BN solid lubricant. On $\mathrm{A} 8 \mathrm{WS}_{2}$ sample, the micrograph indicates the presence of agglomerated solid lubricant in the steel matrix.

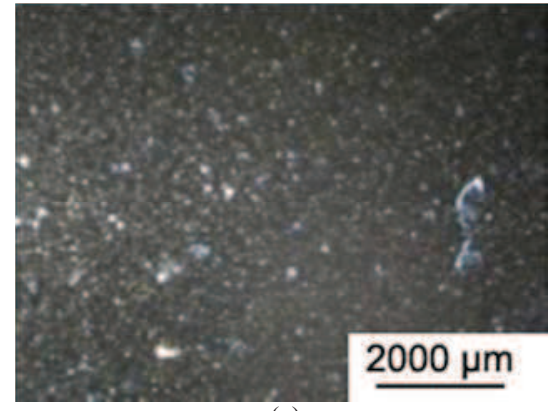

(a)

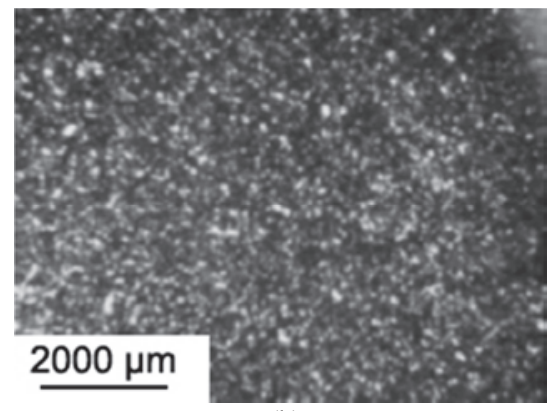

(b)

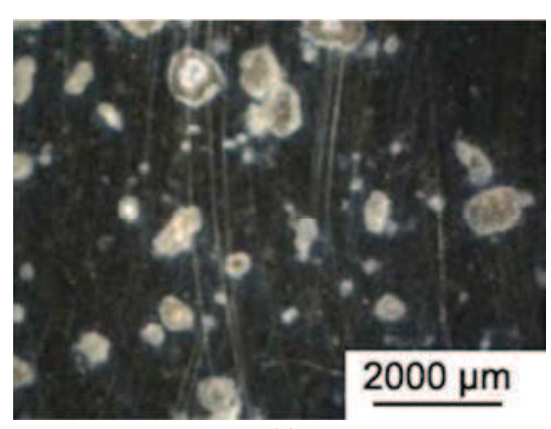

(c)

Figure 4: Optical micrographs of initial surfaces of (a) steel 18-10, (b) A10BN and (c) A8WS 2. 
Sliding surfaces were observed on both samples and sliders using an optical microscope (Fig. 5 to Fig. 9). All of the samples show evidences of strong adhesive transfers of material inside the scar track.

In 18-10 Steel case, reddish and black debris adhere on the two contacting bodies (Fig. 5). Numerous deformation scratches can also be distinguished on all the observed surfaces.

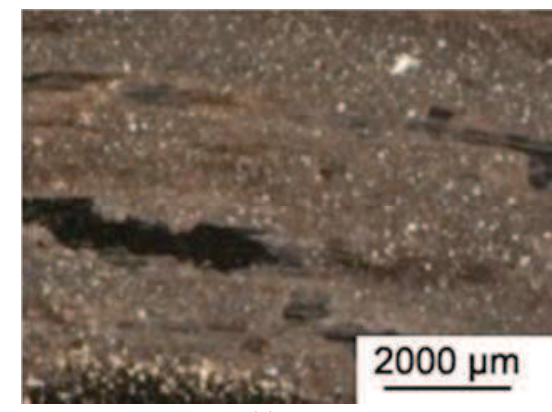

(a)

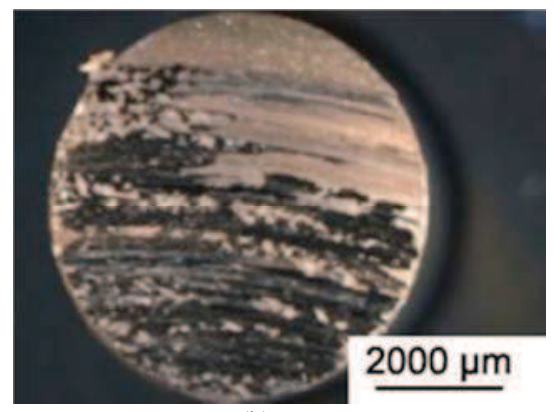

(b)

Figure 5: Binocular microscopy images (a) of the 10-18 steel sample (b) and of the pin.

Composites containing h-BN are affected by a catastrophic wear (Fig. 6 and Fig. 7). Actually, wear depths exceed one millimetre on the disc. Fine particles can be collected in the deep scar of the discs. Particles are sprayed and stuck on both contacting surface. Numerous scratches can be observed on the pins.

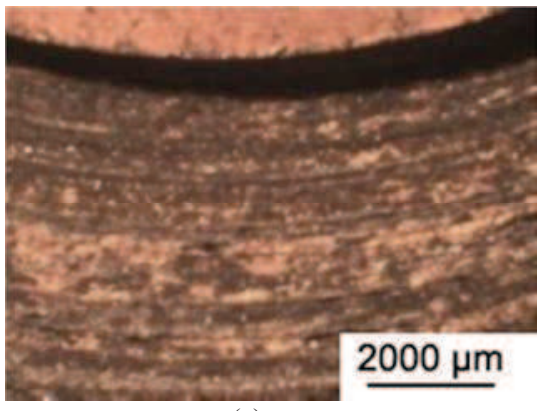

(a)

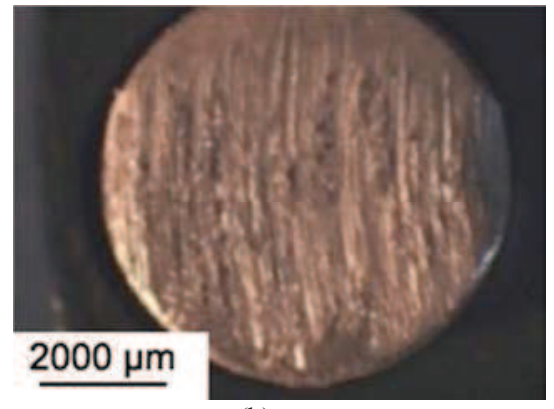

(b)

Figure 6: Binocular microscopy images (a) of A10BN sample (b) and of the pin.

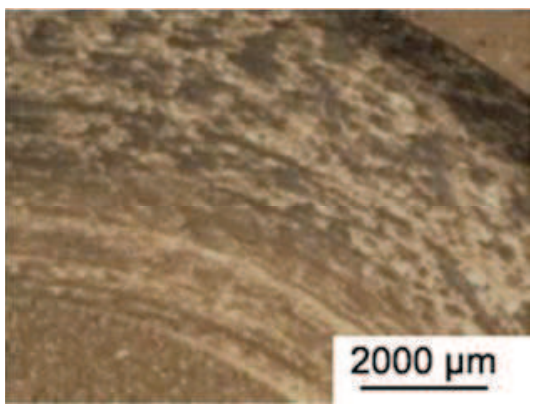

(a)

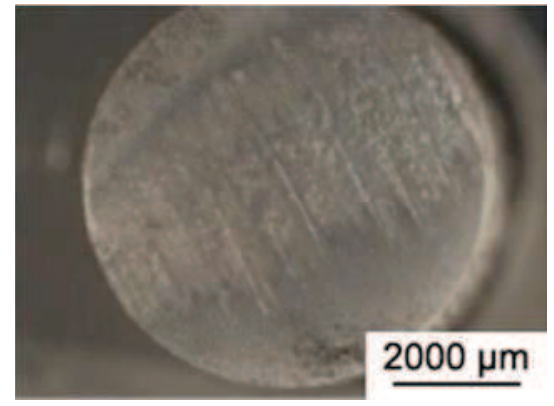

(b)

Figure 7: Binocular microscopy images (a) of A20BN sample (b) and of the pin.

Samples containing $\mathrm{WS}_{2}$ present a similar aspect to that observed on steel samples (Fig. 8 and Fig. 9). Black particles are stuck on both sliders and samples, which form a highly shearing transfer layer crossing by numerous scratches. A rust colour can be distinguished on the two surfaces. 


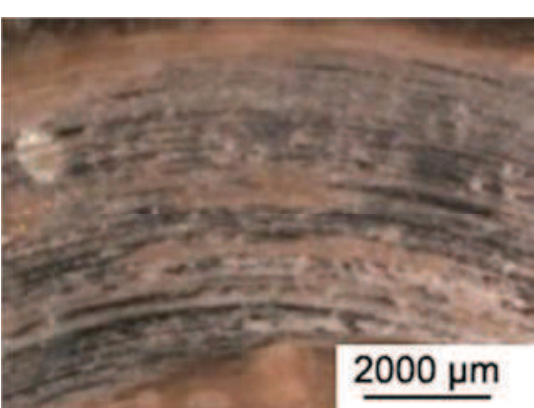

(a)

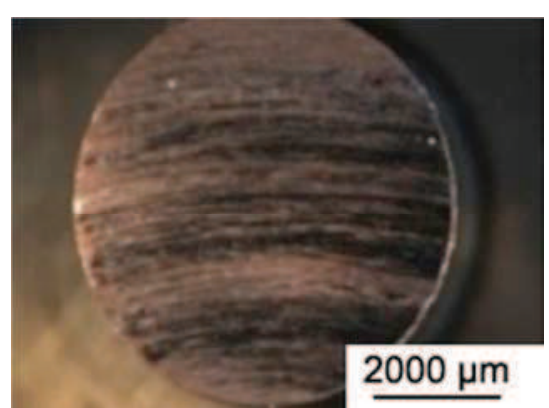

(b)

Figure 8: Binocular microscopy images (a) of the A8WS 2 sample (b) and of the pin.

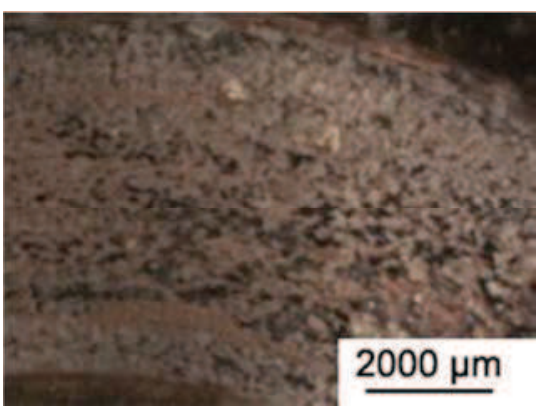

(a)

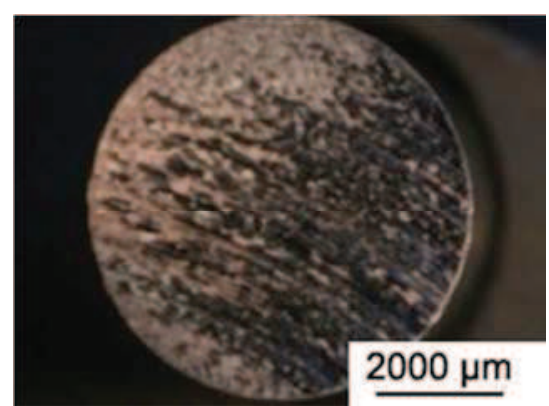

(b)

Figure 9: Binocular microscopy images (a) of the $\mathrm{A} 12 \mathrm{WS}_{2}$ sample (b) and of the pin.

In agreement with the colour changing of the samples, a thermal oxidation mechanism is supposed to occur on all samples. Tribological and thermal oxidation may be taken in account in the rubbing track as a result of the contact dynamics conditions and the environmental temperature of $450^{\circ} \mathrm{C}$.

Topographic measurements are performed on a VYCO NT 1100 optical profiling system. Before tribological tests, pins show arithmetic roughness $\left(R_{a}\right)$ of about $0.14 \mu \mathrm{m}$. Disc roughness is dependent on the material composition. Arithmetic roughness is ranged from $0.06 \mu \mathrm{m}$ for the $18-10$ steel disc to $0.18 \mu \mathrm{m}$ for the steel composite at $20 \% \mathrm{~h}-\mathrm{BN}$.

Table 3 summarizes the arithmetic roughness and rms roughness $\left(R_{q}\right)$ for the sliding pin and the five composites of this study. MMC arithmetic roughness is generally higher than these of the 1810 steel disc. Thus, the polishing preparation led to a relatively smooth surface on steel, while composites exhibit more irregular surfaces.

Steel and MMC surface topography, performed by optical profilometry, shows that the roughness parameters enhance after tribological tests for the overall studied samples. On 18-10 steel, the three-dimensional images reveal very irregular surfaces associated to large deformation scratches (Fig. 10). The corresponding measured arithmetic roughness $R_{\mathrm{a}}$ reaches $4.4 \mu \mathrm{m}$.

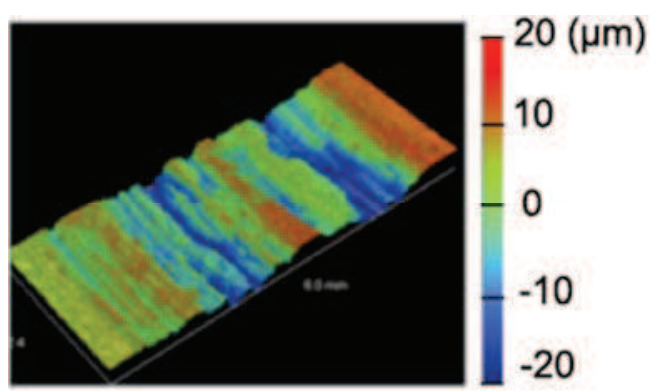

Figure 10: Three-dimensional image of 10-18 steel recorded by optical profilometry. 
Fig. 11 (a) and Fig. 11(b) were recorded inside the deep scars of samples containing h-BN. In these hollows, high roughness parameters are measured: $R_{a}=9.5 \mu \mathrm{m}$ for $\mathrm{A} 10 \mathrm{BN}$ and $R_{a}=10.5 \mu \mathrm{m}$ for A20BN. The powder particles remain present at the surface of these samples.

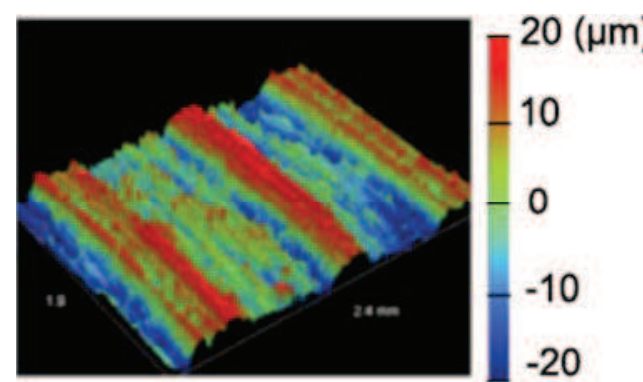

(a)

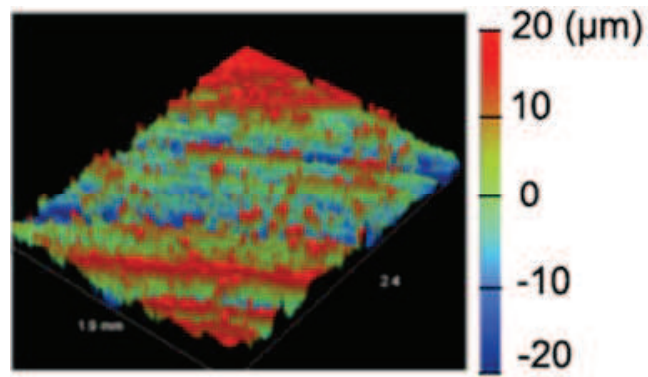

(b)

Figure 11: Three-dimensional images of A10BN (a) and A20BN (b) recorded by optical profilometry.

On samples containing $\mathrm{WS}_{2}$, scratches are less deep and surfaces show a smoother pattern (Fig. 12). The arithmetic roughness $R_{\mathrm{a}}$ is also lower than those of the three previous samples.

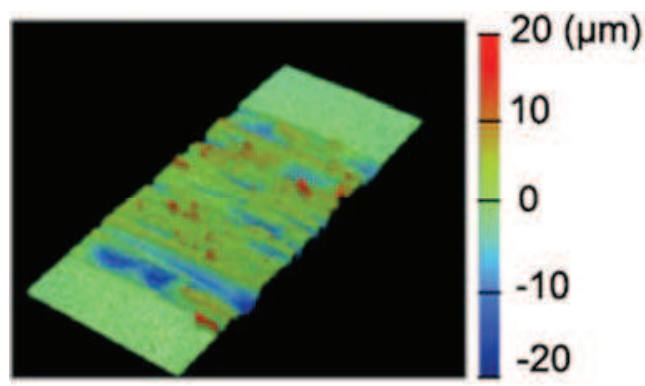

(a)

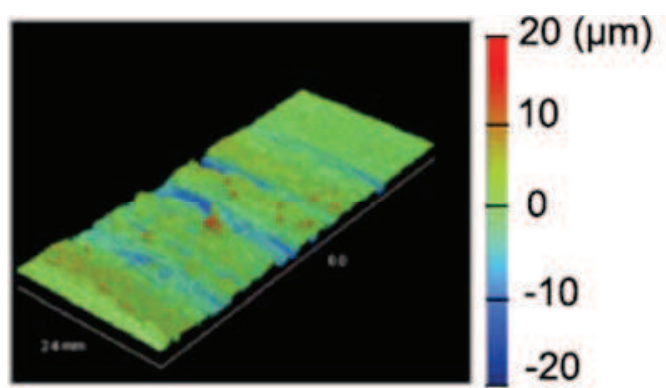

(b)

Figure 12: Three-dimensional images of $\mathrm{A}^{8} \mathrm{WS}_{2}(\mathrm{a})$ and $\mathrm{A}_{12} \mathrm{WS}_{2}$ (b) recorded by profilometry.

Comparison of $R_{\mathrm{a}}$ and $R_{q}$ values before and after tribological tests is given in

Table 3. The difference before and after friction can reach an order of magnitude but roughness parameters for steel containing $\mathrm{WS}_{2}$ give the lowest values.

Table 3: Arithmetic and rms roughness values recorded before and after the tribological tests.

\begin{tabular}{ccc|cc}
\hline Material & \multicolumn{2}{c}{ Before the test } & \multicolumn{2}{c}{ After the test } \\
& $\boldsymbol{R}_{\boldsymbol{a}}[\boldsymbol{\mu} \mathbf{m}]$ & $\boldsymbol{R}_{\boldsymbol{q}}[\boldsymbol{\mu} \mathbf{m}]$ & $\boldsymbol{R}_{\boldsymbol{a}}[\boldsymbol{\mu} \mathbf{m}]$ & $\boldsymbol{R}_{\boldsymbol{q}}[\boldsymbol{\mu} \mathbf{m}]$ \\
\hline \hline Steel 18-10 & 0,06 & 0,09 & 4,39 & 5,99 \\
A10BN & 0,12 & 0,33 & 9,54 & 11,74 \\
A20BN & 0,18 & 0,52 & 10,49 & 13,16 \\
A8WS & 0,12 & 0,18 & 2,98 & 4,25 \\
A12WS & 0,17 & 0,21 & 2,20 & 2,85 \\
\hline
\end{tabular}




\section{Studies of wear and damage}

The three-dimensional images of the sample damages allow a quantitative analysis of the missing volume $V_{-}$(volume below the reference plane defined by the initial undamaged surface) and the displaced volume $V_{+}$(volume above the previous reference plane). The difference between these two volumes gives the wear volume $V_{\mathrm{w}}$ of the studied section. The total wear volume $V_{\mathrm{T}}$ is determined using the following expression, where $r$ is the average radius of the wear track and $l$ is the width of the analysed section:

$$
V_{T}=\mathrm{V}_{w} \cdot \frac{2 \pi r}{l}
$$

Wear rate $U_{w}$ is calculated from the previous total volume values by using the Archard model and assuming that wear is a linear function of covered distance (

Table 4). For the present tests, the wear rates are given by the following formula:

$$
U=\frac{V_{T}}{F_{N} \cdot \sum_{i} v_{i} \cdot t_{i}}
$$

$F_{\mathrm{N}}$ represents the normal load applied to the samples, $v_{i}$ the velocity during the $i^{\text {th }}$ step and $t_{i}$ the duration of the $i^{\text {th }}$ step. Wear rate of $18-10$ steel, $\mathrm{A} 8 \mathrm{WS}_{2}$ and $\mathrm{A} 12 \mathrm{WS}_{2}$ are negatives and with the same order of amplitude. Wear rates calculated for A10BN and A20BN are the highest for all the series and associated to the catastrophic degradation of these samples. The lowest wear rate is measured for composites that contained tungsten disulphide solid lubricant. The endurance of the composites has been improved by the addition of this lubricant in the steel matrix.

Table 4: Wear rate of the studied materials.

\begin{tabular}{cc}
\hline Material & $\begin{array}{c}\text { Wear rate of the disc } \\
{\left[\mu \mathrm{m}^{3} \cdot \mathrm{N}^{-1} \cdot \mathrm{m}^{-1}\right]}\end{array}$ \\
\hline \hline Steel 18-10 & $-7,4 \cdot 10^{2}$ \\
A10BN & $1,8 \cdot 10^{3}$ \\
A20BN & $2,0 \cdot 10^{7}$ \\
A8WS & $-5,6 \cdot 10^{2}$ \\
A12WS & $-5,4 \cdot 10^{2}$ \\
\hline
\end{tabular}

\section{EDX spectrometry and micromorphology analysis}

Micrographs were performed on a Phillips SEM 515 scanning electron microscope, equipped with an electron gun made of a $\mathrm{LaB}_{6}$ crystal. This device also allows the acquisition of energy dispersive X-ray spectra (EDX). The third bodies initially stuck on the sliding tracks, are taken out from their sliding surfaces with a carbon tape. The micrographs reveal different morphology of tribofilms depending on the lubricant content inside the composite.

The third body extracted from the 18-10 steel sliding surface shows broken films of compacted powders and dense clusters with shear zones (Fig. 13). 

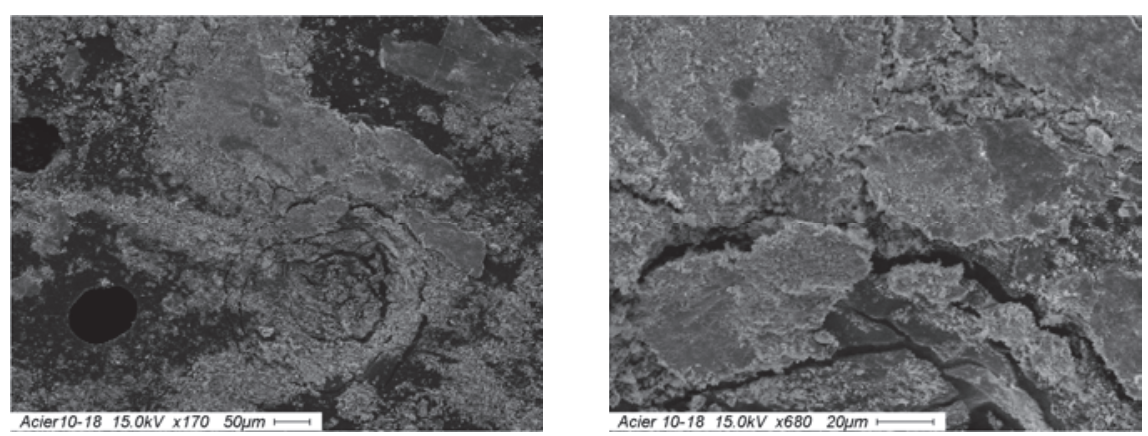

Figure 13: Observations by SEM of the tribological film extracted from the sliding surface of the 10-18 steel sample with two different magnifications.

The third body extracted from MMC containing h-BN solid lubricant (A20BN) also shows powdery particles (Fig. 14). Any agglomerate debris is observed from the third body extract from this sample surface.
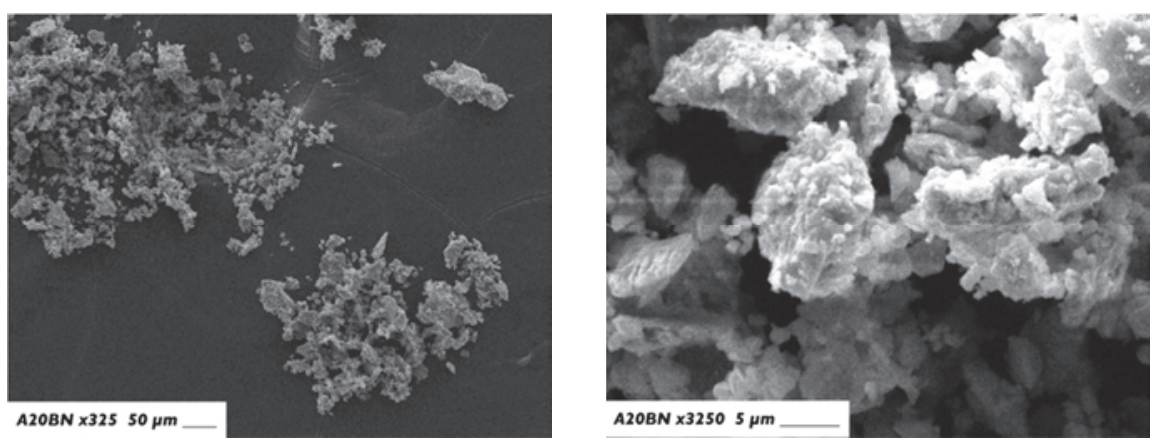

Figure 14: Observations by SEM of the tribological film extracted from the sliding surface of the A20BN with two different magnifications.

Finally, the tribofilm from the composite surface containing tungsten disulphide $\left(\mathrm{A} 12 \mathrm{WS}_{2}\right)$ looks like tribofilms from 18-10 steel, with compacted particles and layers of high sheared (Fig. 15).
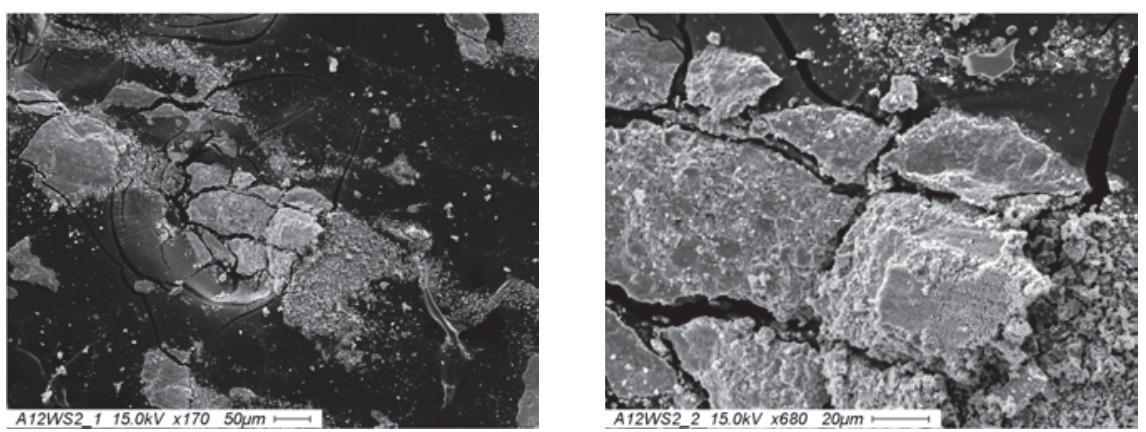

Figure 15: Observations by SEM of the tribological film extracted from the sliding surface of the $\mathrm{A}_{12} \mathrm{WS}_{2}$ with two different magnifications. 
The energy dispersion spectra are performed with an accelerating voltage of $20 \mathrm{keV}$ and a working distance about $28 \mathrm{~mm}$. Spectra clearly show the presence of components of the matrix metal steel, i.e., iron (Fe), chromium $(\mathrm{Cr})$ and nickel $(\mathrm{Ni})$ on the 18-10 steel surface and carbon $(\mathrm{C})$ from the tape (Fig. 18). A peak of oxygen $(\mathrm{O})$ is also detected in relation with the presence of oxidized metallic particles in the tribofilm. The Palladium peaks (Pd) proceed from the surface preparation mode using metallic sputtering before observation.

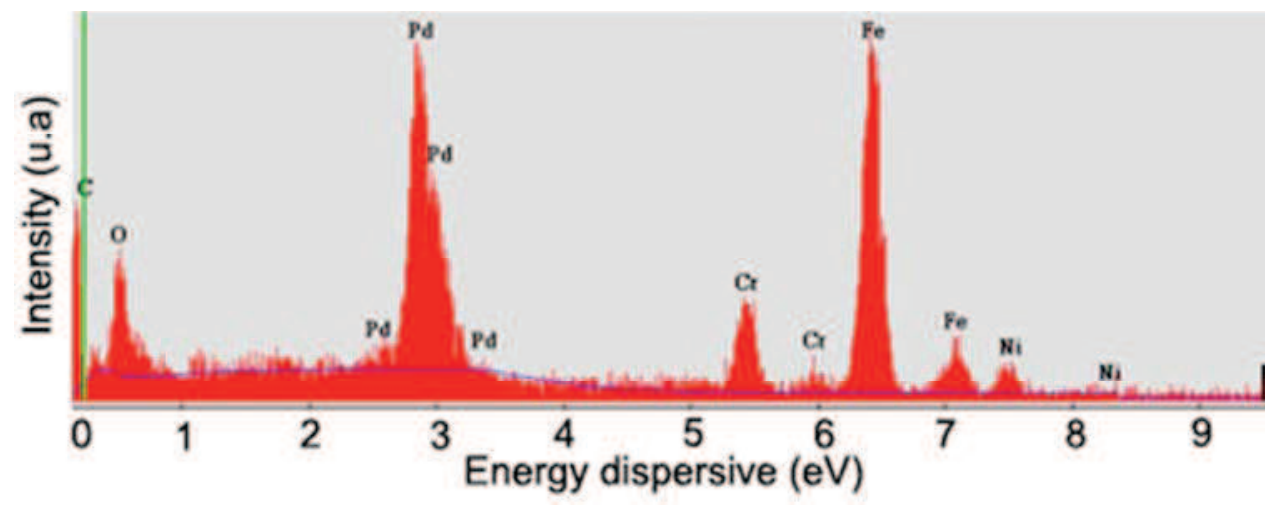

Figure 16: EDX spectrum of 18-10 steel showing elements from the stainless steel ( $\mathrm{Fe}, \mathrm{Cr}, \mathrm{Ni}$, $\mathrm{C})$ and the presence of oxidized zones $(\mathrm{O})$. Metallization was performed $(\mathrm{Pd})$ prior observation.

Characteristic peaks of tungsten (W) and sulphur (S) are detected in the third body extracted from the $\mathrm{A}_{12} \mathrm{WS}_{2}$ sliding surface (Fig. 19). It proves that the solid lubricant was trapped into the tribofilm.

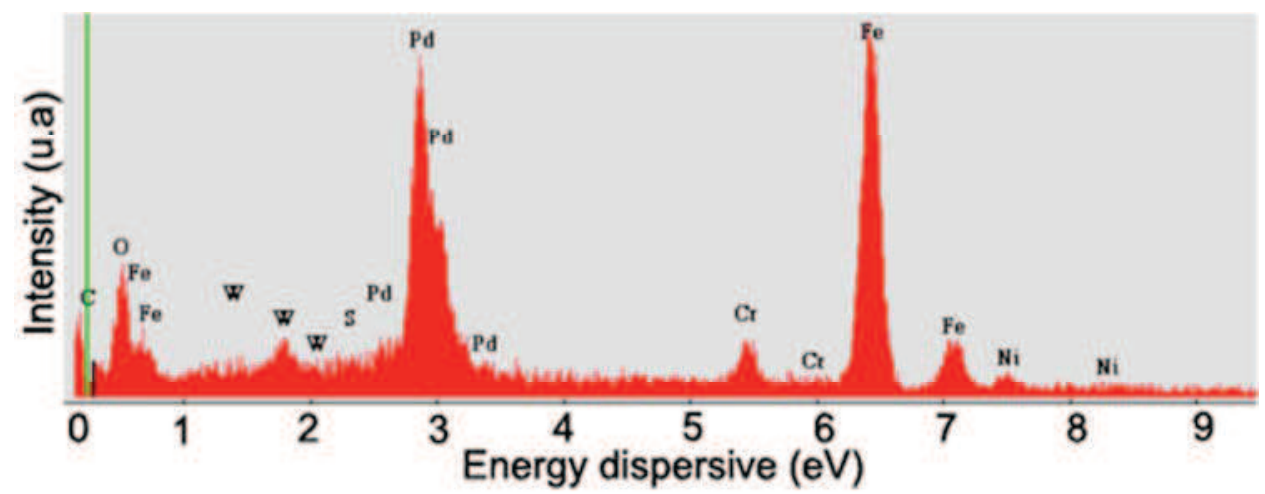

Figure 17: EDX spectrum of the tribofilm extracted from the $\mathrm{A}_{12} \mathrm{WS}_{2}$ sliding surface showing elements from the steel matrix $(\mathrm{Fe}, \mathrm{Cr}, \mathrm{Ni}, \mathrm{C})$ and the solid lubricant $(\mathrm{W}, \mathrm{S})$. 


\section{Discussion}

The topographic, morphological, and chemical analyses revealed the formation of tribofilms during friction tests. Tribological films are produced by production of particles from both pins and discs. This third body mostly consists with steel matrix compounds and solid lubricant, when it's available, but also with metal oxides coming from the sample surfaces.

The 18-10 steel tribofilm is formed both of single debris and agglomerate debris. Furthermore, the overall degradation mechanisms of this steel involve both abrasive wear and adhesive wear associated to an oxidization process. This third body protects the surfaces of the pin and the disc by accommodating the shear stresses.

Depending on the nature of the solid lubricant, two opposites effects are observed on the tribological performances of the third body: degradation or improvement of the tribological properties.

For MMC with h-BN (A10BN and A20BN), friction forces measured during the tests are high and the third body appears as a powder mainly produced by the disc surface. The tribofilm is not cohesive enough and is easily drained out of the sliding track, so that the shear stresses are directly transmitted to the sliding surfaces. The surfaces of discs are continuously sacrificed to produce an unstable tribofilm until the end of the test. In this situation, the surfaces are not protected and degradations are catastrophic.

When the tribofilms contain $\mathrm{WS}_{2}$, instead of h-BN, friction and wear are reduced and debris remains into the contact area. In the same manner than 18-10 steel, the tribofilm is constituted by trapped particles and plates produced by disc and pin surfaces. Moreover, stratified structures are observed in these tribofilms and indicate shear zones inside the third body. Due to the presence of $\mathrm{WS}_{2}$, the third body remains stable and more cohesive that enable it to protect the sliding surfaces efficiently by relaying the most part of the shear stresses. It contributes to adaptation of velocities between the two contacting bodies.

\section{Conclusion}

In order to offer innovative materials for tribological applications at high temperature $\left(450^{\circ} \mathrm{C}\right)$, metal matrix composites (18-10 stainless steel matrix) including solid lubricant particles (different contents of h-BN or $\mathrm{WS}_{2}$ ) were developed using a SPS technique of powder consolidation. Tests were carried out using a rotative Pin-on-disc tribometer at $450^{\circ} \mathrm{C}$ and under varying velocities at a constant load. The identified wear mechanisms essentially correspond to adhesive wear (transfer phenomenon), abrasive wear (numerous scratches) and oxidization of the matrix compounds. The proposed approach takes into account the third body concept, and highlights the ambiguous role of solid lubricant introduced into the matrix on the friction and wear responses. Unlike h-BN, solid lubricant such as $\mathrm{WS}_{2}$ seems to be a good prospect to promote the formation of a stable tribofilm, able to take over the shearing stresses and ensure the velocity adaptation, necessary between the two first bodies. This third body acts as a relay to withstand the severe working conditions.

\section{Acknowledgements}

The authors wish to thank the French Interregional action of Midi-Pyrénées and Aquitaine for its financial support, the $\mathrm{PNF}^{2}$ platform and the CEMES of Toulouse for the synthesis and the development of optimized samples for this study. 


\section{References}

[1] T. Childs, Tribology International, Vol. 13, (1980), p. 285

[2] Y. Watanabe : Contact Characteristics of New Self-Lubricating Composite Materials, (IEICE Trans. Electron., Japan 1994).

[3] M. E. Fine, (1990), Recent Advances in Tribology, Northwestern Univ. ed., Y.C. Chung and H.S. Cheng, Eds., Evanston.

[4] Y. Pauleau, N. Marechal, P. Juliet, C. Zimmermann, and R. Gras, Lubrication Engineering, Vol. 52, (1996), p. 481.

[5] Y. Kimura, T. Wakabayashi, K. Okada, T. Wada and H. Nishikawa, Wear, Vol. 232, (1999), p. 199.

[6] Y. BerthierIn: Handbook of Materials Behavior Models, edited by J. Lemaître, Academic Press, (2001), p. 679

[7] J. Denape, Y. Berthier, and L. Vincent, In: Fundamentals of tribology and bridging the gap between the macro- and micro/nanoscales, edited by B. Bhushan, Kluwer Academic Publishers, (2001), p. 393

[8] K. Inoue. U.S. Patent No. 3,241,956. (1966)

[9] R. Orru, R. Licheri, A. Mario Locci, A. Cincotti, G. Cao, Materials Science and Engineering : R, Vol. 63, (2009) p. 127.

[10] Information on http://pnf2.dr14.cnrs.fr/

[11] A.S. Adamou, J. Denape, J.- Y. Paris, and E. Andrieu, Wear, Vol. 261, (2006), p. 311

[12] A. S. Adamou, Thesis, Institut National Polytechnique de Toulouse, (2005)

[13] G. Amontons, "Du frottement de diverses matières les unes contre les autres" (1699)

[14] J. F. Archard, Journal of applied physics, Vol. 24, (1953), p. 981 